\title{
Identification of types and frequency of pre-analytical errors in hematology laboratory at a tertiary hospital of Nepal
}

\author{
Kricha Pande ${ }^{1}$, Prabesh Dahal ${ }^{1}$, Laxman Pokharel ${ }^{2}$ \\ ${ }^{I}$ Department of Pathology, Nepal Medical College, Teaching Hospital, Kathmandu, Nepal \\ ${ }^{2}$ Department of Biochemistry, Nepal Medical College, Teaching Hospital, Kathmandu, Nepal
}

\section{Keywords: \\ Hematology; \\ Preanalytical error; Quality control; \\ Samples;}

\begin{abstract}
Background: In the laboratory, errors can occur at any stage of sample processing; pre-analytical, analytical, and post-analytical. Since the pre-analytical phase is the most common source of laboratory errors, the goal of this study is to identify the types and frequency of pre-analytical errors in the hematology laboratory.

Materials and Methods: This is a cross-sectional descriptive study done at Nepal Medical College Teaching hospital for a duration of nine months (January 2020 to September 2020). All blood samples received at the hematology laboratory were included whereas biochemistry and special tests blood samples were excluded. Samples were checked for misidentification (incorrectly labeled vials/vials without labels/incorrectly filled forms), incorrect samples (wrong choice of vials), clotted samples, inadequate samples, diluted samples, hemolyzed samples. The errors that occurred in these samples (both inpatient and outpatient) were noted down and measures were taken accordingly before analyzing the sample.
\end{abstract}

Results: The total number of samples received was 15,337. Pre-analytical errors were seen in 857 samples (5.5\%). Inadequate samples (25\%) were the most common error followed by incorrect samples $(20 \%)$, hemolyzed samples (20\%), misidentification (14\%), clotted samples (12\%), and diluted samples (9\%). Complete blood count test was most affected. Samples from the inpatient department were most affected.

Conclusion: The preanalytical error rate in the hematology unit was 5.5\% with an inadequate sample being the commonest error. Most of the errors were seen in the test requested for a complete blood count. Samples from the inpatient department showed the most errors.

\section{Correspondence:}

Dr. Kricha Pande, $M D$

Department of Pathology

Nepal Medical College, Teaching Hospital, Kathmandu, Nepal ORCID ID: 0000-0002-9303-831X

Email: krichapande@gmail.com

Reveived : October $21^{\text {st }} 2020$; Accepted : February $25^{\text {th }} 2021$

Citation: Pande K, Dahal P, Pokharel L. Identification of types and frequency of pre-analytical errors in hematology laboratory at a tertiary hospital of Nepal. J Pathol Nep 2021;11:1842-6. DOI: 10.3126/jpn.v11i1.32399

Copyright: This is an open-access article distributed under the terms of the Creative Commons Attribution 4.0 International License, which permits unrestricted use, distribution, and reproduction in any medium, provided the original author and source are credited.

\section{INTRODUCTION}

The clinical laboratory is a rapidly changing field that has a very strong impact directly on patient's treatment. Even with the advancement and automation in the clinical laboratory, the zero error rate in the quality report has not been achieved to date. Quality assurance in the laboratory is a must to ensure laboratory users of reliable test results with a high degree of precision and accuracy. ${ }^{1}$ Total quality in laboratory medicine should be defined as the guarantee that each activity throughout the total testing process is correctly performed, providing valuable medical decision-making and effective patient care. ${ }^{2}$ 
Laboratory errors can often have serious adverse consequences. Lack of standardized procedures for sample collection accounts for most of the errors encountered within the total testing process. They can also have clinical consequences as well as a significant impact on patient care, especially those related to specialized tests as these are often considered as "diagnostic". ${ }^{3}$ In the laboratory, errors can occur at any stage of sample processing; pre-analytical, analytical, and post-analytical stages. However, evidence shows most of the laboratory errors occur during the preanalytical stage. ${ }^{4-6}$ A pre-analytical error is defined as a rejected specimen (blood or urine sample), which cannot be successfully tested as it does not meet the acceptability criteria of the laboratory or if the sample is not received. ${ }^{7}$ The receipt and processing of specimens are one of the main steps in the pre-analytical stage. Errors in this stage could be due to mislabeling, incorrect test entry, and entering the wrong location. Most of these errors are preventable. ${ }^{4}$

The pre-analytical phase is the stage of greatest risk and is most vulnerable but pre-analytical errors may go undetected until post-analytical validation and interpretation which impacts the good quality report of a laboratory. ${ }^{6,8}$ Recently the test performances have improved and new parameters have been introduced, as well as internal and external quality controls have been used for the monitoring of accuracy to minimize the error rates. ${ }^{9}$

The quality of the report will not be accepted until the laboratory minimizes the pre and post-analytical errors. Proper and timely recognition of these loopholes in quality control will help lead to the correct therapeutic strategy and better patient care. Since pre-analytical errors are not the sole responsibility of the lab and its staff, the management and other staff involved with blood collection should be aware of this problem to minimize the pre-analytical errors hence helping in generating a quality report. Since the preanalytical phase is the most common source of laboratory errors, the goal of this descriptive study is to identify the types and frequency of pre-analytical errors at Nepal Medical College, Teaching hospital.

\section{MATERIALS AND METHODS}

This is a cross-sectional descriptive study done at Nepal Medical College, Teaching Hospital (NMCTH) for a duration of nine months (January 2020 to September 2020). All blood samples received at the hematology unit of the laboratory (samples for complete blood count, coagulation studies, peripheral blood smear, and malarial parasites) during the study period were included whereas biochemistry and special tests blood samples were excluded. Before submitting them to the respective unit, they were checked for mismatching which included: misidentification ( incorrect labeling of vials/ vials without labels/ incorrectly filled forms), incorrect samples (wrong choice of vials), clotted samples, inadequate samples, diluted samples, and hemolyzed samples. The types of error, the place from where the sample was sent (outpatient or inpatient) as well as in which test samples the error has occurred was noted down and measures were taken accordingly before analyzing the samples in automated and semi-automated machines. The data thus obtained was entered in Excel Microsoft and analyzed using SPSS version 16.0. Ethical clearance was taken from the Institutional Review Committee of NMCTH.

\section{RESULTS}

The total number of samples received in the hematology unit was 15,337 samples in nine months duration. Preanalytical errors were seen in 857 samples. Hence, the frequency of pre-analytical errors was $5.5 \%$. Out of 15,337 samples, error-free samples were 14,480 (94.5\%). The different types of errors identified in the hematology unit are tabulated in table 1 . Out of total errors, inadequate samples (219 samples; 25\%) were the most common followed by incorrect samples and hemolyzed samples (169 and 172 samples; $20 \%$ each). The less common errors in descending orders were misidentification (117 samples; 14\%), clotted samples (105 samples; 12\%), and the least common was diluted samples (75 samples; 9\%). Table 2 shows different sources of errors. The samples for complete blood count accounted for most of the sources of errors $(n=553 ; 64 \%)$ followed by coagulation studies $(\mathrm{n}=179 ; 21 \%)$, peripheral blood smear $(\mathrm{n}=111 ; 13 \%)$ and test for malarial parasite in blood smear $(\mathrm{n}=14 ; 2 \%)$.

The rejected samples were traced whether they were from the in-patient department (IPD; ward samples) or outpatient department (OPD). Out of 15,337 samples, most of the samples were from OPD (8351 samples; $54 \%$ ) followed by IPD (6986 samples; 46\%). It was found out that out of 857 rejected samples, 809 samples $(94 \%)$ were from IPD whereas 48 samples $(6 \%)$ were from OPD. The inadequate sample was the most common error in both IPD as well as OPD. Among IPD, hemolyzed samples ( $\mathrm{n}=168,2.40 \%)$, incorrect sample $(\mathrm{n}=158,2.26 \%)$, clotted sample $(\mathrm{n}=103$, $1.47 \%)$, misidentification $(\mathrm{n}=102,1.46 \%)$ and diluted samples $(n=75,1.07 \%)$ were the samples with error. Among OPD cases, errors were seen as misidentification $(n=15$, $0.17 \%)$, incorrect samples $(\mathrm{n}=11,0.13 \%)$, hemolyzed samples $(n=4,0.04 \%)$ and clotted samples $(n=2,0.02 \%)$.

\begin{tabular}{|c|c|}
\hline Types of error & Number of samples with error $(n ; \%)$ \\
\hline Misidentification & $117(14 \%)$ \\
\hline Incorrect samples & $169(20 \%)$ \\
\hline Inadequate samples & $219(25 \%)$ \\
\hline Clotted samples & $105(12 \%)$ \\
\hline Diluted samples & $75(9 \%)$ \\
\hline Hemolyzed samples & $172(20 \%)$ \\
\hline \multicolumn{2}{|c|}{$\begin{array}{l}\text { Total number of samples: } 15,337 \\
\text { Total number of samples with error: } 857 \text { (5.5\%) }\end{array}$} \\
\hline
\end{tabular}


Table 2: Different sources and percentage of each pre-analytical error

\begin{tabular}{lc}
\hline Sources of error & Number (n; \%) \\
\hline Complete blood count & $553(64 \%)$ \\
Coagulation test & $179(21 \%)$ \\
Peripheral blood smear & $111(13 \%)$ \\
$\begin{array}{l}\text { Malarial parasite test in } \\
\text { blood smear }\end{array}$ & $14(2 \%)$ \\
Total & $\mathbf{8 5 7 ( 1 0 0 \% )}$ \\
\hline
\end{tabular}

Diluted samples were not received in OPD samples. The distribution of pre-analytical errors among IPD and OPD is tabulated in table 3 .

\section{DISCUSSION}

The increase in the prevalence of medical errors represents a disturbing trend; hospital-based errors are the eighth leading cause of death in the United States. ${ }^{10}$ Clinical laboratories have long focused their attention on quality control methods and quality assessment programs dealing with analytical aspects of testing. ${ }^{11}$ The phases before the sample reaches the laboratory (preanalytical) and the phase after the sample is analyzed (post-analytical) are equally important. ${ }^{12}$ However, the preanalytical phase is challenged with many shortcomings like improper filling up of request forms with illegible handwriting, improper blood collection by the staff, and improper mixing up of blood with anticoagulant, etc. ${ }^{13}$ The total number of samples received in hematology was 15,337 during nine months duration. Out of these samples, 857 samples were rejected with an error rate of $5.5 \%$ which is higher than other studies. Following are different rates of error found in different studies: Sakyi et a $\mathrm{l}^{14}(4.7 \%)$, Chawla et $\mathrm{al}^{13}(1.9 \%)$, Upreti et $\mathrm{al}^{15}(1 \%)$, Arul et $\mathrm{al}^{5}(0.43 \%)$, and Rajalakshmi et $\mathrm{al}^{16}(0.3 \%)$. The higher rate of an error occurring in the present study may be because only the hematology unit of whole laboratory samples was taken into account in this study. Since the error rate is significantly higher than the error rates of other studies, there seems a need to educate the staff dealing with phlebotomy. A similar study by HarsimranKaur et $\mathrm{a}^{11}$ concluded that pre-analytical errors were frequent in laboratories and can be corrected by regular analysis of the variables involved. Rectification of these types of errors could be done by regular education of the staff.

Out of total errors, an inadequate sample was the most common error followed by incorrect samples and hemolyzed samples. The inadequate sample was most often error even in a study by Singla et $\mathrm{al}^{17}$ and Arul et $\mathrm{al}^{5}$ Appropriate knowledge regarding the important role of proper labeling of the samples should be made known to all the staff involved in the collection as it is the most common form of error seen in this study. Since samples from the hematology unit were only taken into account, most of the errors were found out to be occurring in the samples collected for complete blood
Table 3: Percentage of pre-analytical errors inpatients and out-patients samples

\begin{tabular}{lcc}
\hline Types of error & IPD (n; \%) & OPD (n; \%) \\
\hline Total samples & $6986(46 \%)$ & $8351(54 \%)$ \\
Misidentification & $102(1.46 \%)$ & $15(0.17 \%)$ \\
Incorrect samples & $158(2.26 \%)$ & $11(0.13 \%)$ \\
Inadequate samples & $203(2.9 \%)$ & $16(0.19 \%)$ \\
Clotted samples & $103(1.47 \%)$ & $2(0.02 \%)$ \\
Diluted samples & $75(1.07 \%)$ & - \\
Hemolyzed samples & $168(2.4 \%)$ & $4(0.04 \%)$ \\
Total samples & $\mathbf{8 0 9}(\mathbf{9 4 \% )}$ & $\mathbf{4 8 ( 6 \% )}$
\end{tabular}

counts followed by coagulation studies.

The present study showed a vast difference between the error rates in between samples from OPD and IPD. Most of the errors occurred from samples collected from IPD (94\%) which is significantly higher than the samples collected from the OPD. This variation may be due to the collection of blood samples by laboratory technicians if the samples were collected from OPD whereas the inpatient samples were collected by the ward staffs hence, there seems a dire need to arrange for the workshop and training program for all those involved in sample collection to reduce the preanalytical errors which are completely human dependent. The main areas of training should be focused on phlebotomy methods as well as about the adequacy of the sample, how to not let the sample be hemolyzed, and proper filling of the requisition forms. This trend of higher error rates among the samples of inpatient departments is seen in other studies as well. Kadic et a ${ }^{18}$ stated that the proportion of inpatient rejected samples was 8.7 fold higher than in the outpatient samples.

Rajalakshmi et $\mathrm{al}^{16}$ stated that adequate training, regular maintenance of records of errors, and periodic auditing will result in effective reduction of such errors with improvement in the overall performance of laboratory works. Ying et al ${ }^{19}$ emphasized applying a training system between various departments whereas Lippi et $\mathrm{al}^{20}$ gave much importance to standardization and monitoring preanalytical variables which will be associated with the most efficient and wellorganized laboratories resulting in reduced operational costs and increased revenues. Tadesse et $\mathrm{al}^{21}$, Wiwanikit et $\mathrm{al}^{22}$, Plebani et $\mathrm{al}^{23}$, and Boon et $\mathrm{al}^{24}$ gave importance to the close communication between clinicians and laboratory personnel to improve laboratory quality in general. Hence, a training session and interdepartmental communication should be organized to reduce the error rates.

\section{CONCLUSIONS}

The preanalytical error rate in the hematology unit was $5.5 \%$ with an inadequate sample being the commonest error. Most of the errors were seen in the test requested for a complete blood count. The error rate was very high in 
samples collected from IPD. To minimize this error, training session and interdepartmental communication is a need of time. Since laboratory work is a product of teamwork, the main areas of training should be focused on phlebotomy methods as well as about the adequacy of the sample, how to not let the sample be hemolyzed, and proper filling of the requisition forms.

\section{Acknowledgment}

I would like to thank all the colleagues and laboratory technicians from the Department of Pathology as well as the Department of Biochemistry for their help during the study period.

\section{Conflict of interest: None}

\section{REFERENCES}

1. HarsimranKaur VN, Selhi PK, Sood N, Singh A. Preanalytical Errors in Hematology Laboratory- an Avoidable Incompetence. Iran J Pathol. 2016 ;11(2):151-4. Website.

2. Lippi G, Becan-McBride K, Behúlová D, et al. Pre-analytical quality improvement: in quality we trust. Clin Chem Lab Med 2013;51:229-41. Crossref

3. Magnette A, Chatelain M, Chatelain B, et al. Pre-analytical issues in the haemostasis laboratory: guidance for the clinical laboratories. Thromb J 2016;12:49. Crossref

4. Al Saleem N, Al-Surimi K. Reducing the occurrence of errors in a laboratory's specimen receiving and processing department. BMJ Qual Improv Rep 2016;5:u211474.w4624. Crossref

5. Arul P, Pushparaj M, Pandian K, et al. Prevalence and types of pre-analytical error in hematology laboratory of a tertiary care hospital in South India. J Lab Physicians 2018; 10:23740. $\underline{\text { Crossref }}$

6. Simundic AM, Lippi G. Pre-analytical phase-a continuous challenge for laboratory professionals. Biochem Med 2012;22:145-9. Crossref

7. Salinas M, López-Garrigós M, Yago M, et al. Quality assessment for pre-analytical phase in clinical laboratory: a multicentric study. Rev Calid Asist 2011;26:264-8. $\underline{\text { Crossref }}$

8. De la Salle B. Pre- and post analytical errors in hematology. Int J Lab Hematol 2019;41 Supp11:170-6. $\underline{\text { Crossref }}$

9. Méndez A, Bargetzi M, Huber A, et al. Pitfalls and challenges of the pre-analytical phase in hematology. Ther Umsch 2013;70:449-55. Crossref
10. Green SF. The cost of poor blood specimen quality and errors in pre-analytical processes. Clin Biochem 2013;46:1175-9. Crossref

11. Plebani M. Errors in clinical laboratories or errors in laboratory medicine? Clin Chem Lab Med 2006;44:750-9. Crossref

12. Carraro P, Plebani M. Errors in a stat laboratory: Types and frequencies 10 years later. Clin Chem 2007;53:1338-42. Crossref

13. Chawla R, Goswami B, Tayal D, et al. Identification of the types of preanalytical errors in the clinical chemistry laboratory: 1-Year Study at G.B. Pant Hospital. Lab Med 2010;41: 89-92. $\underline{\text { Crossref }}$

14. Sakyi A, Laing E, Ephraim R, et al. Evaluation of analytical errors in a clinical chemistry laboratory: a 3 year experience. Ann Med Health Sci Res 2015;5:8-12. $\underline{\text { Crossref }}$

15. Upreti S, Upreti S, Bansal R, et al. Types and frequency of pre-analytical errors in haematology lab. J Clin Diagn Res 2013;7:2491-3. $\underline{\text { Crossref }}$

16. Rajalakshmi V, MuthuKrishnan R, Rajeswari K, et al. Identification of the types of pre-analytical errors in a hematology laboratory: 1 year study at ESIC hospital, Chennai. Trop J Path Micro 2017;3:272-5. Crossref

17. Singla P, Parkash AA, Bhattacharjee J. Pre-analytical error occurrence rate in clinical chemistry laboratory of a public hospital in India. Clin Lab 2011;57:749-52. PMID: 22029191.

18. Kadić D, Avdagić Ismić A, Hasić S. The prevalence of preanalytical errors in the laboratory of the Cantonal Hospital Zenica in Bosnia and Herzegovina. Med Glas 2019;16:1-6. DOI: 10.17392/979-19.

19. Ying Li H, Yang YC, Huang WF. Reduction of pre-analytical errors in laboratory by establishment and application of training system. J Evid Based Med 2014;7:258-62. $\underline{\text { Crossref }}$

20. Lippi G, Chance JJ, Church S, et al. Preanalytical quality improvement: from dream to reality. Clin Chem Lab Med 2011;49:1113-26. $\underline{\text { Crossref }}$

21. Tadesse H, Desta K, Kinde S, et al. Errors in the hematology laboratory at St. Paul's Hospital Millennium medical college, Addis Ababa, Ethiopia. BMC Res Notes 2018;11: 420. $\underline{\text { Crossref }}$

22. Wiwanitkit V. Types and frequency of preanalytical mistakes in the first Thai ISO 9002:1994 certified clinical laboratory, a 6-month monitoring. BMC Clin Pathol 2001; 1:5. Crossref 
23. Plebani M, Chiozza ML. Audit in laboratory medicine. Eur24. Boon DJ. Evaluating laboratory performance. Arch Pathol J Clin Chem Clin Biochem 1996;34:655-7. PMID: 8877343. ～Lab Med 1988;112:354-6. PMID: 3355332. 